ด

columns of psychiatry's relationship with the pharmaceutical industry' (Psychiatric Bulletin, March 2005, 29, 81-83) as we feel it has much relevance for developing countries such as Sri Lanka. It appears that the pharmaceutical industry employs different methods when dealing with developing countries; these include the provision of poor details of products which sometimes lead to deleterious effects.

The pharmaceutical industry and the medical profession mainly interact through the sales promotion of drugs and symposia organised by pharmaceutical companies. The industry influences prescribing patterns through drug promotion but, if interactions between doctors and drug companies are transparent, no impropriety will be alleged (Breen, 2004).

Large scale commercial trials are still not conducted in Sri Lanka although help is often given informally (either money or equipment). However this may change as more companies look towards developing countries to carry out clinical trials because of the low cost and availability of human resources.

Research funded by pharmaceutical companies is less likely to be published and is more likely to have an outcome favourable to the sponsor (Lexchin et al, 2003). Nevertheless, the interaction between academia and the pharmaceutical industry is valuable but should be regulated by academic departments (Montaner et al, 2001)

In many developing countries clinicians rely on drug treatment more than in the west due to a shortage of human resources for time-consuming psychological therapies. However, although psychiatrists in developing countries may be more vulnerable to undue influence by pharmaceutical companies, we believe that the governing ethical principle that our primary obligation is to the patient will guide us to be independent and help us follow rational prescribing practices

BREEN, K. J. (2004) The medical profession and the pharmaceutical industry: when will we open our eyes? Medical Journal of Australia, 180 $409-410$.

LEXCHIN, J., BERO, L. A., DJULBEGOVIC, B., et al (2003) Pharmaceutical industry sponsorship and research outcome and quality: systematic review. BMJ, 326, 1167-1170.
MONTANER, J. S. G., O'SHAUGHNESSY, M.V. SCHECHTER, M. T. (2001) Industry-sponsored clinical research: a double-edged sword. Lancet, $\mathbf{3 5 8}$ 1893-1895.

${ }^{*}$ K. A. L. A. Kuruppuarachchi Professor of Psychiatry, T. S. Lawrence Lecturer in Psychiatry, Faculty of Medicine, University of Kelaniya, Ragama, Sri Lanka

\section{Lessons from the UK diamorphine shortage}

The article by Luty (2005), together with the two commentaries (Carnwath, 2005 Gilvarry, 2005), does much to reveal the intricacies of the debate concerning injectable diamorphine prescribing. Unfortunately, none of the articles mentions the fact that since December 2004 supplies of injectable diamorphine in the UK have been diverted away from addiction services due to a failure in production at the plant of the main manufacturer: Chiron.

In Cornwall we had 51 clients in receipt of such a prescription, all of whom had already been tried on optimised methadone maintenance, and two-thirds of whom were stable and not using street drugs. When the shortage started to affect our local pharmacies, 43 of these clients were converted to a part-injectable methadone prescription. All 43 complained of side-effects and, using a questionnaire, keyworkers identified other 'serious undesirable consequences' in 41 , with 35 clients admitting to increasing or restarting street heroin use. Clients who were not switched to methadone had diamorphine solution or tablets, or higher strength ampoules, which were on the whole much better tolerated.

The experience has confirmed to local clinicians the value of diamorphine by whatever route, particularly in those that do not tolerate methadone well.

The disruption that has been caused by the supply failure has been considerable and we have been disappointed that the Department of Health appears to have had so much difficulty in procuring adequate additional supplies, or even in giving a reliable date as to when normal supplies will return. This uncertainty is adding considerably to the ongoing difficulty of planning safe and effective treatment for our clients.

CARNWATH,T. (2005) Heroin prescription: a limited but valuable role. Psychiatric Bulletin, 29, 126-127.

GILVARRY, E. (2005) Commentary on: New guidelines for prescribing injectable heroin in opiate addiction. Psychiatric Bulletin, 29, 128-130.

LUTY, J. (2005) New guidelines for prescribing injectable heroin for opiate addiction. Psychiatric Bulletin, 29, 123-125.

Rupert White, David Cox, Ben Charnaud Consultants, Cornwall Drug and Alcohol Team, Tolvean House, Redruth, Cornwall TR15 2SF

\section{Do we really need a duty consultant?}

As much as I would like to agree with Riordan's proposal that consultant psychiatrists provide only telephone advice rather than a conventional out-ofhours service (Psychiatric Bulletin, May 2005, 29, 193-194), I am afraid he does not take into account one of the core duties when on call. This involves carrying out assessments under the Mental Health Act 1983 for which there is no alternative than a face-to-face interview. In my experience most requests come from police stations for assessments of people who have been taken to the cells as a place of safety if they appear to be suffering from a psychiatric disorder or have been arrested for an offence. Recent British Medical Association guidance (BMA, 2004) emphasises the desirability of using alternatives to prosecution, such as admission to hospital, where detainees have a psychiatric disorder and it is not in the public interest to prosecute. Without a duty consultant available to make direct mental state examinations, these patients and other urgent cases in the community would be left suffering overnight which, depending upon their risk behaviours, could result in potentially disastrous outcomes.

BMA \& ASSOCIATION OF FORENSIC PRACTITIONERS (2004) Healthcare of Detainees in Police Stations. London: BMA.

Syed Husain Consultant Forensic Psychiatrist Sandalwood Court, Highworth Road, Swindon SN3 4WF 